2020, Volume 14, International Conference Innovative Business Management \& Global Entrepreneurship (IBMAGE 2020), pages: 701-714 |

https://doi.org/10.18662/lumproc/ibmage2020/51

\section{Choosing the Hotel According to the Quality Presented by Influencers on Social Networks}

\section{Corina Aurora MARIN (BARBU)', Elena CONDREA2*}

${ }^{1}$ Bucharest University of Economic Studies, Bucharest, Romania. coribarbu@,yahoo.com

${ }^{2}$ Ovidius University of Constanta, Faculty of Economic Sciences, Constanta, Romania, elenacondrea2003@yahoo.com

* Corresponding Author
Abstract: The tourism industry has found an incredibly fertile ground to reach potential customers with the growth of social media. With the influencers' tendencies to share moments in their lives and especially about their travels, social networks have become one of the most powerful weapons that travel agencies and hotels use to attract as many customers as possible. The phenomenon of influencers is one in development in our country as well. New accounts are constantly appearing on social networks, promoting brands from many fields (beauty, fashion, cooking, sports and even tourism). We are witnessing a revolution in the consumption of audiovisual content, and the development of the concept of influencer confirms this.

The main purpose of this paper is to explore how influencers can influence consumers' decisions in choosing a hotel. It will focus on research on attitudes and opinions on social media and information in tourism in Romania. The data were collected through an online opinion poll and were analyzed using descriptive statistics. Research has shown a great advantage in using influencers to attract customers. However, customers who choose certain hotels through influencers come with higher expectations, which is why the quality of services must rise to the highest standards.

Keywords: tourism industry; influencers; quality; social media.

How to cite: Marin (Barbu), C.A., \& Condrea, E. (2020). Choosing the Hotel According to the Quality Presented by Influencers on Social Networks. In M. W. Staniewski, V. Vasile, \& A. Grigorescu (vol. ed.), Lumen Proceedings: Vol. 14. International Conference Innovative Business Management \& Global Entrepreneurship (IBMAGE 2020) (pp. 701-714). Iasi, Romania: LUMEN Publishing House.

https://doi.org/10.18662/lumproc/ibmage2020/51 


\section{Introduction}

Promoting products and services by influencers is one of the most effective online marketing methods nowadays. For the professionals at the top of the decision making process of the purchasing team, the newest and most important form of approach is marketing through influencers [1].

Social media has served as the perfect platform to share personal experiences, often accompanied by photo and video evidence, which has given the feeling of authenticity and credibility and made this style of usergenerated content embraced quite quickly [9]. Combining this new way of circulating information with the low costs of social media and their overall coverage, marketers have begun to use these benefits for their own gain, by integrating social media into their marketing strategies and stimulating conversations between potential customers.

In this context, the social media plays an important role in promoting tourism. Influencers have also a very important part in the decision-making behavior of customers who choose a place to go or where to stay. Content created by influencers on a trip or vacation is easily posted on social networks such as Facebook, Instagram, YouTube and have a strong impact on people who see it. Much of this impact comes from the informality of those messages and their more private and relaxed approach.

Thus, today the hotel industry has seen a substantially change, due to the fast development of the online social platforms, therefore creating brand new ways of improving and attracting customers by facilitating communication and involving influencers.

\section{Theoretical context}

Nowadays, it is crucial for hospitality companies to constantly evolve and improve the quality of the services they provide continuously. The development is a consequence of the fact that this sector is one of the most economically productive. On the other hand, its place in the world economy forces this sector to comply and evolve with market requirements. Thus, quality is the key element for every hotel to develop and respond to customer requirements and desires.

In this context, the use of modern marketing techniques and the promotion of the quality offered is itself a component of quality. The use of social media channels to promote services, as well as influencers, is a plus for the hotel industry and any hotel must implement an online promotion system and adapt to market requirements. 
Singh et al. defines the Social Influence Marketing as "a technique that uses social media (content created by everyday people using highly accessible and scalable technologies such as blogs, message boards, podcasts, microblogs, bookmarks, social networks, communities, wikis and vlogs) and social influencers (everyday people who have a wide influence on their peers, by virtue of how much content they share online) to meet the marketing and business needs of an organization" [8].

The name influencer refers to either a person with a relevant number of followers, or a person who has different passions, who is remunerated by various brands to promote them and present the products to followers who trust their opinions, in exchange for an amount of money or free products. [6]. The most used social networks for such marketing strategies are: Instagram, YouTube, Facebook and Snapchat.

The reasons why influencers have power over consumers are diverse. Studies have shown that it depends on the consumers' trust in the influencers, and this can be determined by their level of experience. For example, an influencer who is only from a certain field will be perceived as having more authority and credibility in his field than other people. If this authority of influencers is strengthened by a large number of followers and appreciations, then they will give even more credibility to consumers. Another reason is the attractiveness of people on social media. In the subconscious, people feel more attracted to charismatic people and this brings a positive association between the person and the brand and the decision to buy a certain product becomes much easier [2].

Nowadays, the digital influencers are claiming that they can have a crucial role in the demographics presented above, and are able to even create content which is customized and post it on YouTube, Facebook, Instagram, Twitter, personal blogs, Snapchat or worldwide known platforms such as Trip Advisor, booking.com, etc. They have the ability to create brand awareness for hospitality-related properties [7]. In the context of a variety of hotels and rising prices, influencers have a role to play in guiding consumers' choices when they want to find a hotel to their liking.

Instagram is the social platform, on which most influencers work for the tourism and hospitality industry. With more than 100 million monthly active users, Instagram is the go-to platform for people who are in search of travel ideas [9]. The contribution that each consumer bring to various platforms simplifies the cooperation between communities with corresponding thinking and tastes in consumption. By doing this, they expect to speed-up the process in which they have to take various decisions when travelling [4]. 
Therefore, influencers work with hospitality stakeholders in order to promote and reach the audience niche, more efficiently than any other environment, and generate profits for the companies involved. This power that influencers have come from the social media which has the ability to access and distribute the information globally.

A high number of researches have been implemented on different topics which are concerning the behavioral attributes of consumers on social networks. Still, there is a positive part of having an active part as a business administrator on these online platforms. The fact that the hotel's e-services has received a vigorous response, it generates a direct impact on performance and quality. The favorable evaluation and good reviews on well-known sites, increase the chances of booking up to $13.5 \%$ of the services offered [4].

Hotel managers' decision makers should always actively keep up and diversify their business strategy in order to secure the succession and continued positive development of their business. Their lack of interest towards the customer satisfaction evaluation system, can lead to a very unfavorable impact on customers, to the hotel's reputation and last but not least, profits, as in our days, almost all potential customers do their research online, on social platforms, in order to make the reservation. Because online reputation management helps build customer trust as well as managing any negative presence, hotels need to consider their online presence.

The influencers' public frequently blindly regards them as specialists or experts in the respective field of interest and gives them full confidence in the information provided. Thus, their use to promote hotel quality can be a real strategy to attract customers. The hotel industry has learned that it benefits greatly from the use in their marketing advertising of influencer, especially among the younger people who are highly influenced, as they arrange their holidays exclusively based on social media posts and photos.

The Google Travel Study by „The 2014 Traveler's Road to Decision" has listed the travel and hotel industry as the ideal industry for influencers, demonstrating that the internet is mostly used when people have to take decisions regarding leisure and travel, more so when the primary goal is to attract young people, like millennials and generation Z. Having an influencer as a promoter for the hotel brand and the accommodation that it offers, can attract a high amount of awareness and recognition, leading to enhanced revenues [5].

Influencers are seen by consumers as a "more credible celebrity version", which means they trust them. The moment that an influencer exposes his holiday image which took place in a hotel or resort of his choice, there is a very high possibility that his followers will also take into 
consideration visiting that place. As a hotelier, it is fundamental not to resist those forces of influence, but instead to collaborate with them and accept them. The newest generation of reviewers come from the influencers who can offer a real image of the hotel's location through all the content that it displays on social media. They have the ability to reach potential customers, and sharing with them on a personal level impressions and building lasting and trusting relationships with the people who follow them.

\section{Research methodology}

The present analysis incorporates the filtered results of an extensive literature review but is relying primarily on fundamental research. It is largely based on a phenomenological paradigm, which was viewed as the best form in order to understand the human behavior from the partaker's own perspective. The study also has at the base a positivist paradigm towards the identification and understanding of the social phenomena that underlie the behavior regardless of the subjective situation of the individual.

The research on the attitude of the hotel services consumer towards influencer marketing is a descriptive research because we wanted to make an image of the subject in order to find out to what extent influencing determines the choice of a hotel. In general, two types of research methods are used: the quantitative and the qualitative method. We used the quantitative method in this research, because it is a precise way.

Therefore, for the verification of the hypotheses formulating the present analysis, we used a quantitative method of data collection and interpretation, namely the questionnaire. With its help we were able to collect information about the opinions of different people regarding the impact that influencers can have in choosing a hotel.

In order to allow for a more precise scientific quantification and measurement, where it is possible, and subjective perspective and in-depth understanding of positions and impressions, when there is necessary.

Starting from the premise that influencer marketing is perceived differently by consumers, the selective nature of perception not allowing a unity of opinion, we developed a questionnaire to answer very precise questions through the multiple choice answer.

Choosing the sample of respondents, targeted the consumers of hotel services, who follow influencers on social media and who travel in the country, in order to obtain the most truthful answers.

In order to respond in a professional manner to the desired result, I chose to use this research method, addressing the questionnaire to a number of 200 people, to know their perception of the relevant characteristics in the 
choices they make. The questionnaire consists of a number of 25 questions. The study was conducted online, and the participants were between 18 and 60 years old, with an average age of 37 years.

The starting point of this study was the formulation of hypotheses, which refer to: (Î1) influencers have the power to influence the choice of a hotel; (Î 2) quality is relevant in choosing a hotel; (Î 3) hotel guests chosen through the promotion made by influencers are satisfied with the choice made; (I 4 ) customers remain loyal to the hotel services they have benefited from.

Table 1. Questions that correspond to the hypotheses

\section{Hypotheses}

\section{Questions}

\begin{tabular}{|c|c|}
\hline I1 & Î1, Î2, î̉, î4, Î9, Î22, Î23 \\
\hline $\mathbf{I 2}$ & Î10, Î11, Î12, Î13, Î15, î 20 \\
\hline I3 & Î16, Î17, Î18, Î19, Î 21 \\
\hline I4 & 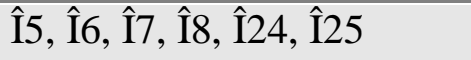 \\
\hline
\end{tabular}

Source: done by the author

\section{Results}

Thus, following the application of the questionnaire, the desire to choose a hotel was identified only because it was visited and promoted by a certain influencer. The respondents have as a major reason for making certain decisions to buy hotel services that when influencers post content with beautiful pictures of the hotel where they stayed, they get inspiration. Respondents agreed that they are also inspired by influencer marketing, but the decision to stay in a particular hotel is not always created only through influencer marketing, but in combination with personal needs and desires.

For a better interpretation of the results and for a better accuracy of them, as well as for understanding the behavior of the consumers, we made a distinction of respondents according to age, education and occupation (see table 2).

Table 2. The respondents' socio-demographic characteristics

\begin{tabular}{|l|l|l|l|}
\hline & Category & $\begin{array}{l}\text { No. } \\
\text { respondents }\end{array}$ & of Percentage \\
\hline \multirow{2}{*}{ Age } & $18-25$ & 79 & $39,5 \%$ \\
\cline { 2 - 4 } & $25-35$ & 52 & $26 \%$ \\
& $35-45$ & 42 & $21 \%$ \\
\hline
\end{tabular}




\begin{tabular}{|l|l|l|l|}
\hline \multirow{2}{*}{ Education } & $45-60$ & 27 & $13,5 \%$ \\
& Medium studies & 43 & 21,5 \\
\cline { 2 - 4 } & College & 119 & $59,5 \%$ \\
\cline { 2 - 4 } & Master & 38 & $19 \%$ \\
\hline \multirow{2}{*}{ Occupation } & Pupil & 22 & $11 \%$ \\
\cline { 2 - 4 } & Student & 47 & $23,5 \%$ \\
\cline { 2 - 4 } & Employee & 131 & $65,5 \%$
\end{tabular}

Source: done by the author

Processing the results obtained from the application of the questionnaire, for the first question almost all the answers were affirmative. Only 4 people did not know what the term influencer was, while 196 knew what an influencer was. All in all, influencers are viewed as the people who have the possibility of affecting the purchasing trends of others, only due to their genuine or apparent authority, wisdom, position or relationship.

Social media influencers earn on the Internet with their work and permanent and active presence in the online environment. They form a reputation based on the number of followers they have. The more people are followed, the better known and appreciated they become. Most of the respondents to the questionnaire follow at least one profile of an influencer. Certainly, the rest of the respondents follow on social networks at least one influencer without knowing this.

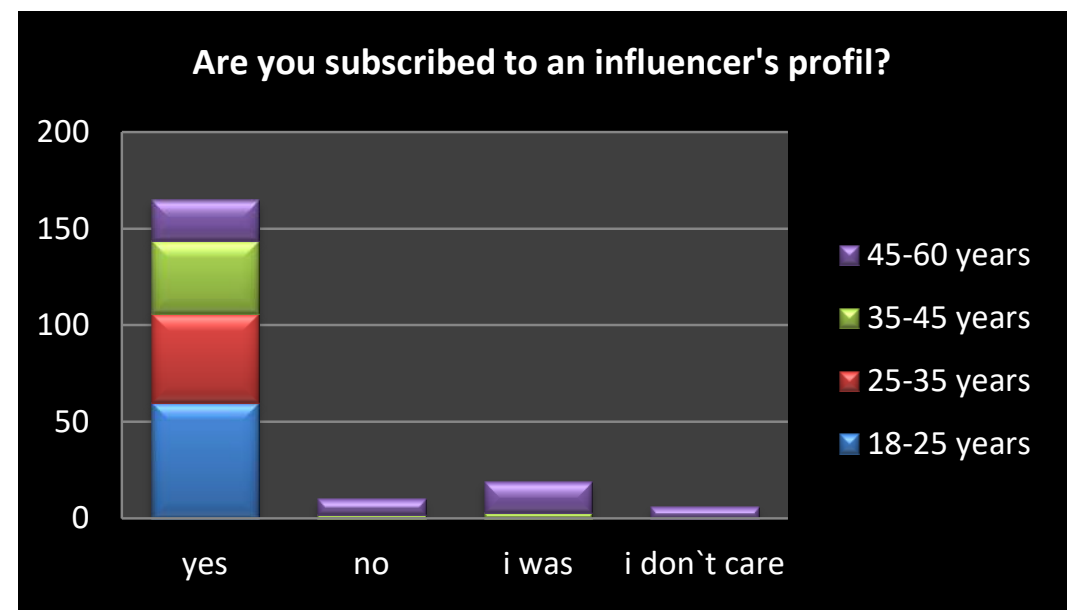

Source: done by the author 
Given the fact that influencers use strategies to get closer to their audience and gain their trust, it gives influencers great importance, especially the young audience. Thus, according to the results obtained, most of the respondents offer both importance and confidence to influencers. Only 35 of the respondents consider that influencers are not important people and 18 that they are not trustworthy, while 103 people consider influencers to be reliable people and 79 consider that only some of the influencers can be trusted.

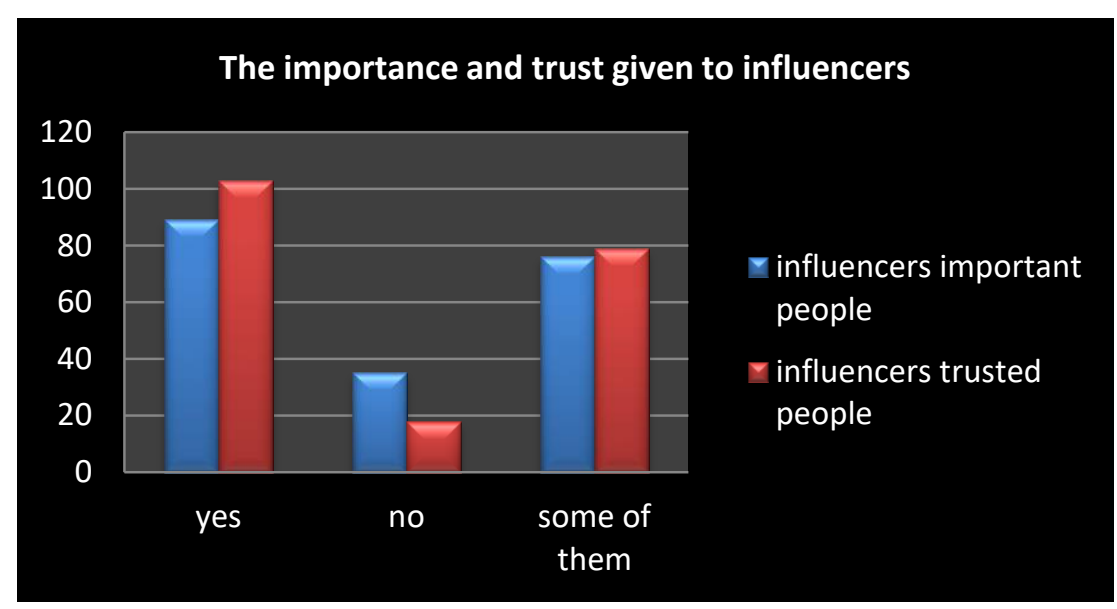

Source: done by the author

Regarding the role of influencers in terms of respondents, 72 of them believe that influencers need to offer positive examples to their followers. A number of 64 respondents believe that the role of influencers is to promote products of different types in the online environment and 34 respondents believe that influencers have the role of influencing the general behavior of followers, not just the referring to choices. Finally yet importantly, 30 of the respondents consider that the role of influencers' posts is only to obtain an income for them.

In the marketing literature, only the intention to buy a product or service is considered to be one of the most important and primary notion which is studied in this field. The interest of marketing researchers for the purchase intention comes from its belonging to the consumer's buying behavior. Intentions are considered strong predictors of future results. Intention and acquisition are indicators of the degree to which people are willing to approach a certain buying behavior. 
Most respondents chose to stay at least once in a hotel promoted by influencers in the online environment. Thus, 54 respondents chose only once to benefit from the hotel services promoted by influencers, 97 of them chose to stay at a hotel promoted online by influencers at least once, while 42 of the respondents chose several times the hotel they stayed at through the prism of an influencer. Only 7 people chose not to be inspired when choosing a hotel by influencers.

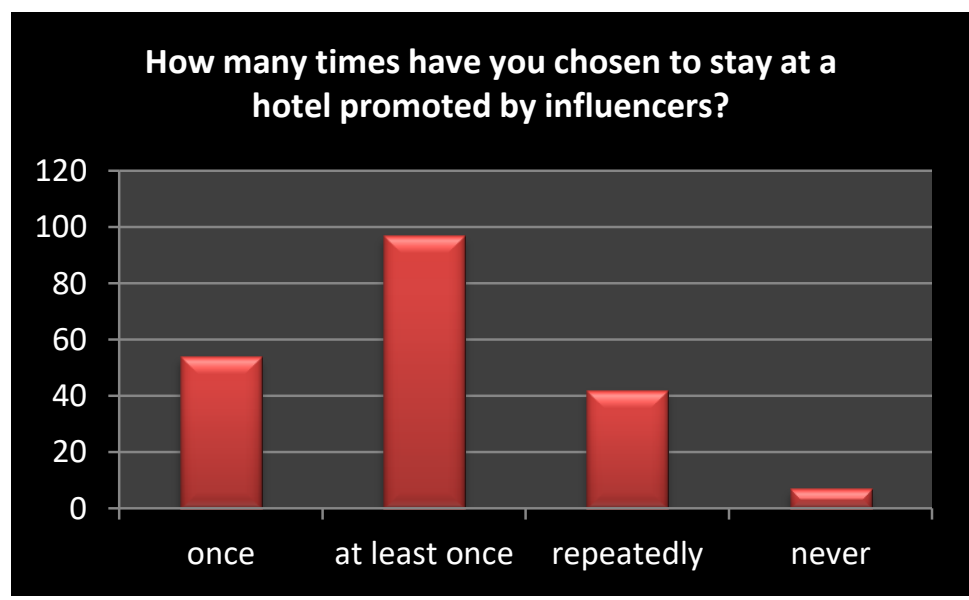

Source: done by the author

Quality plays an important role in the process of promoting the hotel and attracting customers, because they want what they see on social networks to match what they receive from the hotel they are staying at. Hotel services must meet the wishes and needs of the consumer to strengthen his desire to visit the hotel. Quality in the hotel industry is paramount and is a necessary condition for success and survival in today's competitive environment.

Respondents who chose the hotel services promoted by influencers were satisfied in terms of quality and quality/price ratio. We consider that their expectations were met and the services they received corresponded to the expectations created by the posts of the influencers they follow. 


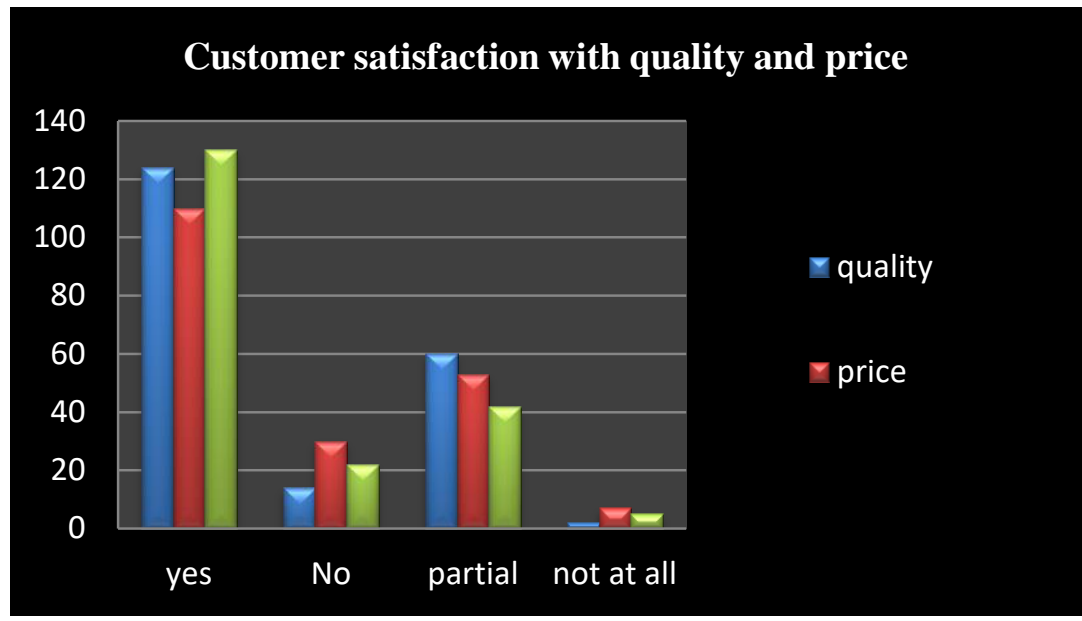

Source: done by the author

Consumers expect hotel brands to make contacts, to establish relationships. The before mentioned trend offers influencers the possibility to possess even more power than ever. With the help of a collaboration with the right influencer, the hotels can establish a dialogue with the targeted audience segments. The possibility of linking certain brands with the perfect influencer, is the perfect liaison and at the same time the most important condition necessary for customer loyalty. This is also demonstrated by the current study, with $42 \%$ of respondents stating that they would choose the same hotel again based on its promotion on the internet by influencers. However, $24 \%$ of respondents would no longer visit the same hotel, and $34 \%$ say they only sought to satisfy a momentary desire.

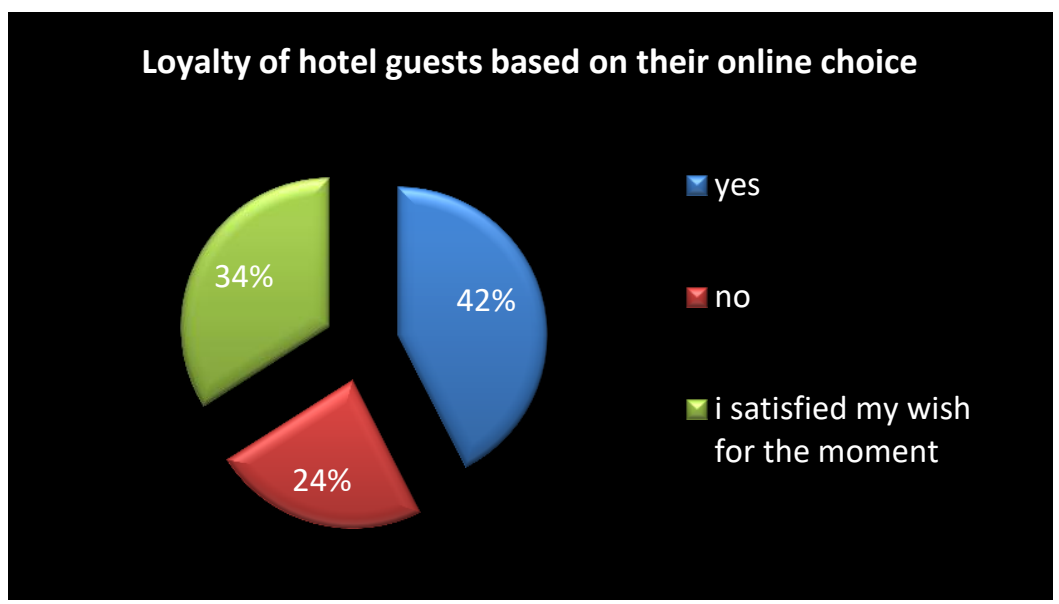

Source: done by the author 
Research shows that respondents have a buying behavior based on the component of affectivity, which generates trust, so that their buying decision is directly or indirectly influenced by the promoters of influencers that give them credibility. The graph below shows the main factors that influence people's behavior when making the decision to stay in a hotel promoted by an influencer.

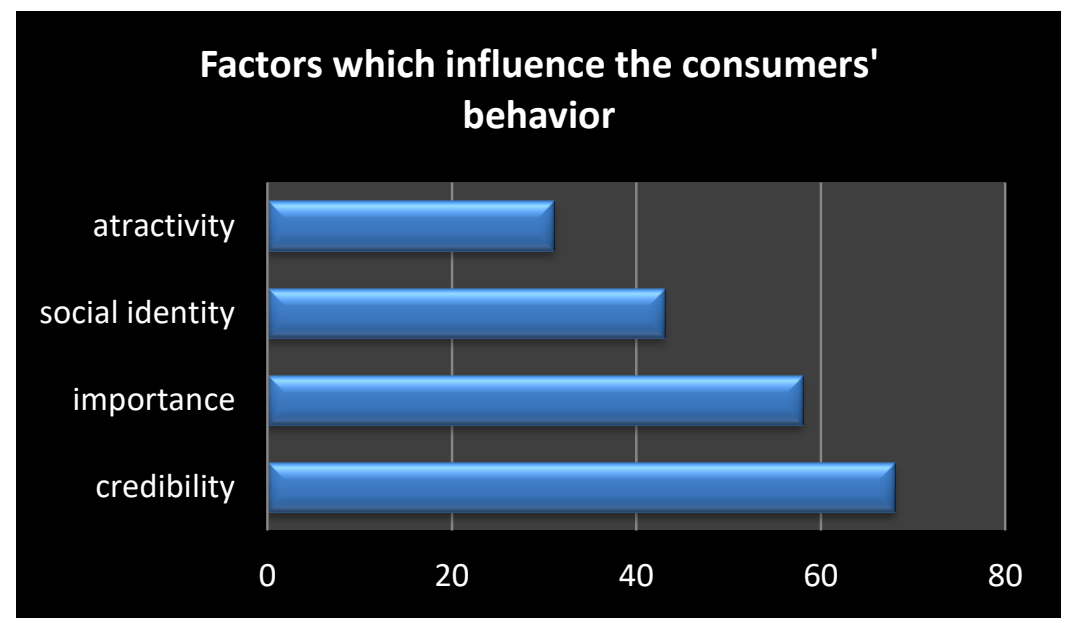

Source: done by the author

A good association between a consumer and the influencer, as well as between the influencer and the promoted hotel services, can capture the consumer's attention and increase the awareness of the service, which could lead to a purchase. Regarding the study, it was found that this factor has the least influence on the consumers' behavior. However, this influence can appear even if the consumer has not been looking for a certain type of accommodation from the beginning and may not even realize exactly what he wants, what he is looking for. As a result, the consumer's attention is drawn to the brand behind the hotel service that the influencer presents.

An influencer works as an idol of consumption because it illustrates how a consumer can do the same things as the influencer. As influencers connect with consumers, sharing information about their personal lives, consumers have a sense that they can relate better to their live [3]. This is more identified among young respondents who follow the profile of certain influencers and want to be like them. The fact that young people feel similar and are inspired by an influencer determines a greater motivation to imitate him and, therefore, to stay in the same place where he stayed. 
Also, the choices of consumers participating in the study are based on the importance given to influencers. They are seen as important people, examples to follow and, consequently, the services they promote are advantageous acquisitions from their point of view.

Credibility is the most important decision-maker factor among respondents. Trust plays a key role in analyzing an influencer's recommendations and opinions. I believe that this reason is the basis of the respondents' buying process because in order to purchase a hotel service based on a recommendation, you must first have trust in the person promoting it. The very role of influencers is to create a confident, credible framework for their followers. The transparent presentation of their lives aims to determine credibility and obtain positive feedback. What the influencer is trying to achieve is the presentation of hotel services in a more humane form that stimulates empathy and affectivity, this determining consumer confidence.



Source: done by the author

Therefore, hypotheses 1, 2 and 3 have been validated, so that consumers who participated in the study are guided in the process of choosing and purchasing hotel services by the recommendation of an influencer, being subscribed to his account and trusting what he promotes. Quality is also an important component for them when choosing a hotel.

Hypothesis 4 was invalidated after applying the questionnaire because the respondents do not become loyal to the hotels where they stayed. 
The purpose of this research has been achieved. We determined that the purchasing behavior of hotel service consumers is influenced especially among young people.

\section{Proposals and recommendations}

Taking into consideration what the study demonstrates, the influencer has the great power of influencing the acquisition decisions of other people, due to his authority, awareness, stance, or connection to its followers. It is important to note that these individuals are not simple marketing tools, but rather content creators and social relationships with the target audience, with whom hotels can collaborate to achieve their marketing goals.

The value of using influencers is recognized in the hotel industry but selecting them for use in a campaign can be difficult. It is therefore recommended that the decision to enter into a partnership between the hotel and the influencer take into account: the results it wants to achieve through its influencer marketing campaign, the target audience, the platform on which it wants to promote and establish a clear picture of what qualities the influencer should have.

Thus, it is recommended for a hotel to track down the influencers who suit best with their crowd. The marketing which involves influencers is development characterized as daring and productive, while it uses the power of the social networks to reduce noise and send notices to the right guests. This is exactly what the influencers are doing, which is targeting the most important guests and linking them to the hotels. Consequently, the moment that a person comments or shares a message on a respective hotel page, that same message will also be visible on their own pages and become visible to their friends.

\section{Conclusions}

Marketing through the help of influencers, is becoming more and more sought-after with each year that passes, and many companies in the hotel industry are seeing customer interest grow as sales increase through the use of public people in their campaigns. The influencers have constructed their trustworthiness and authority on a substantial category of fans. Presenting the experience in a hotel with the help of influencers can help manage and link with the targeted audience.

From the moment that the hostel industry has become more and more involved in the digital make-over of travel purchasing decisions, 
visitors have entirely changed the way they book their hotels, by using social networks to uncover and make a decision to buy the desired hotel services. The impact of the social media on the efficiency and reputation of a hotel is undeniable. The fact that hotels have started to be more active in the environment presented above has offered the hotel industry the chance to distribute hotel information more easily and to better comprehend the customers and all interest groups, thus giving them a stronger, closer and more straightforward relationship with them.

\section{References}

[1] Brown D, Hayes N. Influencer Marketing, Who really influences your customers? UK: Elsevier Ltd; 2008.

[2] Fastenau J. Under the Influence: The Power of Social Media Influencers. 2018

[Online] Available from: https://medium.com/crobox/under-theinfluence-the-power-of-social-media-influencers-5192571083c3

[3] Weinswig, D. Influencers Are The New Brands, Available from: https://www.forbes.com/sites/deborahweinswig/2016/10/05/influencers -are-the-new-brands/?sh=2d7106f27919

[4] Huang D, Li Z, Mou J, Liu X. Effects of flow on young Chinese consumers' purchase intention: a study of e-service scape in hotel booking context. Information Technology \& Tourism. 2017; 17(2):203-228. Available from: https://doi.org/10.1007/s40558-016-0073-0

[5] Ipsos MediaCT. The 2014 Traveler's Road to Decision. Think with Google. Accessed [13/07/2019] from:

https://storage.googleapis.com/think/docs/2014-travelers-road-todecision research studies.pdf

[6] Landsverk KH. The Instagram Handbook: 2014 Edition. Londra: Prime Head; 2014.

[7] Litvin SW, Goldsmith RE, Pan B. A retrospective view of electronic word-ofmouthin hospitality and tourism management, International Journal of Contemporary Hospitality Management. 2008; 30(1). Available from: 10.1108/IJCHM-08-2016-046

[8] Singh S, Diamond S. Social Media Marketing For Dummies. For Dummies; 2012

[9] Terttunen A. The influence of Instagram on consumers' travel planning and destination choice. (Bachelor thesis). Helsinki, Finland: Haaga-Helia University of Applied Science; 2017, Available from: https://www.theseus.fi/bitstream/handle/10024/129932/Terttunen_Ann a.pdf? sequence $=1$ \&is Allowed $=\mathrm{y}$ 